\title{
Pulp Revascularisation of a Non-Vital Immature Young Permanent Tooth - A Case Report and Literature Review
}

\author{
Tanvi Sanjay Satpute ${ }^{1}$, Jayeeta Sidharth Verma² ${ }^{2}$ Jimish Rajiv Shah³ ${ }^{3}$ Aditya Kiran Shinde ${ }^{4}$ \\ 1,2,3,4 Department of Conservative Dentistry and Endodontics, \\ MGM Dental College and Hospital, Kamothe, Navi Mumbai, India.
}

\section{INTRODUCTION}

Traumatic injuries to an immature permanent tooth may result in cessation of dentin deposition and root maturation. Novel revascularisation endodontic procedure (REP) has been considered as an option for treatment of immature teeth with damaged pulp tissue. The continuous development of the root and the root canal has been recognised as a major advantage of this technique over traditional apexification approach. Traditional apexification procedures may resolve pathology but have not been able to prove tooth survival due to absence of continued root development and risk of root fracture. A successful REP results in resolution of signs and symptoms of pathology, radiographic signs of healing, proof of continued root development as well as presence of pulp vitality due to the regeneration of pulp tissue in the root canal. Currently, repair rather than true regeneration of the 'pulp-dentine complex' is achieved and further root maturation is variable.

According to Glossary of Endodontic terms published by American Association of Endodontists, REP's are biologically based procedures designed to physiologically replace damaged tooth structures, including dentin and root structures, as well as cells of the pulp-dentin complex.1,2 Apexification treatment has been a routine procedure to treat and preserve such teeth for many decades. ${ }^{3}$ Apexification is the process by which a suitable environment is created within the root canal and periapical tissue to allow for the formation of a calcific barrier across the open apex. Calcium hydroxide $[\mathrm{Ca}(\mathrm{OH}) 2]$ has been the material of choice for apexification as Frank reported its capacity to induce physiological closure of immature pulpless teeth in 1966.4

However, this technique has several disadvantages, including the unpredictability of apical barrier formation and the long duration of treatment, which often requires multiple visits. ${ }^{5}$ A retrospective study by Jeruphuaan et al. ${ }^{6}$ has shown a higher survival rate with regenerative endodontic treatment when compared to both mineral trioxide aggregate (MTA) and $\mathrm{Ca}(\mathrm{OH}) 2$ apexification. The first evidence of regeneration of dental tissues was in 1932 by G.L. Feldman, who showed evidence of regeneration of dental pulp under certain optimal biological conditions. ${ }^{7}$ In 1971, a pioneer study in regenerative endodontics conducted by Nygaard-Ostby concluded that bleeding induced within a vital or necrotic canal led to resolution of signs and symptoms of necrotic cases and in certain cases, apical closure. ${ }^{8}$ According to Windley et al. (2005), the successful revascularisation of immature teeth with apical periodontitis is mainly dependent upon: 1 . Canal disinfection 2. Scaffold placement in the canal for the growing tissues 3. Bacteria-tight sealing of the access opening. ${ }^{9}$ The purpose of this case report is to illustrate the outcome of a revascularisation endodontic procedure in a non-vital immature young permanent central incisor.
Corresponding Author: Dr. Tanvi Sanjay Satpute, Mn-6, Flat no. 11, Kashish Park,

Near Tip Top Plaza, L. B. S Marg, Thane West - 400604, Maharashtra, India. E-mail: tanvisatpute@gmail.com

DOI: $10.14260 / j e m d s / 2021 / 181$

How to Cite This Article:

Satpute TS, Verma JS, Shah JR, et al. Pulp revascularisation of a non-vital immature young permanent tooth - a case report and literature review. J Evolution Med Dent Sci 2021;10(11):845-848, DOI: 10.14260/jemds/2021/181

Submission 10-11-2020,

Peer Review 22-01-2021,

Acceptance 28-02-2021,

Published 15-03-2021.

Copyright (c) 2021 Tanvi Sanjay Satpute et al. This is an open access article distributed under Creative Commons Attribution License [Attribution 4.0 International (CC BY 4.0)] 


\section{PRESENTATION OF CASE}

A 12-year-old female patient reported to a private practice at Mumbai, Maharashtra, India; with the chief complaint of discolouration in upper front tooth region and she gave a history of trauma at the age of 8 years. Pain was localised, nonradiating and dull in nature. Her medical history was noncontributory. Extra orally, a draining sinus was detected. Clinical examination revealed Ellie's class IV fracture of tooth number 11. Cold test was done, and it showed negative response compared to the left central incisor and upper right lateral. There was no tenderness to percussion or palpation. Gingival tissues were healthy with normal texture, and periodontal probing was within normal limits.

Radiographic examination revealed that tooth number 11 had incomplete root formation (Figure 1). There was incomplete root development with parallel root walls. Periapical changes were also seen.

\section{FINAL DIAGNOSIS}

Pulp necrosis in tooth number 11.

\section{DISCUSSION OF MANAGEMENT}

The treatment plan was to try revascularisation of the tooth in an attempt to promote root maturation in length and width. The treatment plan was discussed with the patient's guardian. Potential risks, complications and benefits of the suggested treatment were explained, and consent was signed.

The tooth was anesthetized with $2 \%$ lidocaine and 1:100,000 epinephrine. Under rubber dam isolation, an access cavity was prepared on tooth number 11 (Figure 2) and the coronal pulp tissue was removed. The canal was irrigated with sodium hypochlorite $(\mathrm{NaOCl})$ (Prime Dental, India) and normal saline solution, and passively instrumented with manual K-files (Kerr, Romulus, MI, USA) up to the apparent length of the tooth subtracted by $2 \mathrm{~mm}$, and irrigation was done with saline solution. Triple antibiotic paste of ciprofloxacin (Cifran $500 \mu \mathrm{g}$; Ranbaxy Laboratories Ltd., Mumbai, India), metronidazole (Metrogyl $400 \mu \mathrm{g} ; \quad$ J.B. Chemicals, Mumbai, India), and minocycline (Minoz $50 \mu \mathrm{g}$; Ranbaxy Ltd., Mumbai, India) with equal proportions was prepared, mixed with distilled water (B.E Products), and placed into the canal to a depth of $2 \mathrm{~mm}$ short of the apex using an endodontic plugger (Mani, Japan), followed by temporary tooth restoration by Cavit (3M ESPE, Germany) for 21 days (Figure 3).

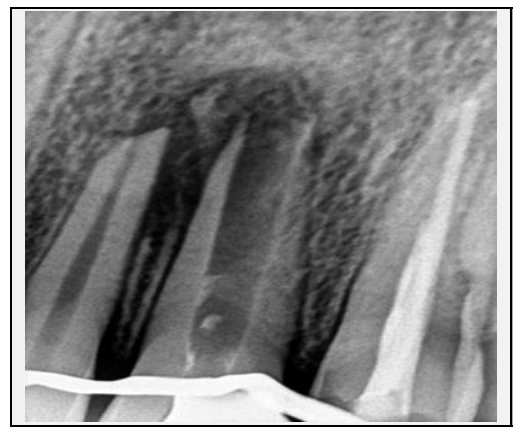

Figure 1.

Pre-Operative

Radiograph Showing

Incomplete Root

Formation

On the second visit, after 21 days, the tooth was re-entered \& irrigated with $2.5 \%$ sodium hypochlorite and rinsed with normal saline. The canal was then dried with paper points. A \#40 K-file was used to irritate the apical tissues to induce bleeding into the root canal. The bleeding was allowed to reach the cervical part of the canal. Ten minutes later, after the formation of a blood clot, white MTA (Dentsply Tulsa Dental, Tulsa, OK, USA) was mixed and placed over the clot carefully. A moistened cotton pellet was placed over MTA and the tooth was restored temporarily with Cavit. (Figure 4)

One day later, the treatment was completed with double seal of glass ionomer cement (GIC) (Ketac Molar Easymix 3M ESPE) restoration on MTA for permanent restoration of the tooth. A baseline radiograph was taken. Patient was recalled every 6 months for clinical and radiological evaluation.

At $6^{\text {th }}$ month, the patient reported with no signs and symptoms. On radiographic examination, there was slight thickening of the dentin walls and an increase in root length. There was a reduction in the periapical radiolucency. (Figure 5)

Patient next reported on the $14^{\text {th }}$ month. At 14 th month, radiograph showed appreciable thickening of dentinal walls. There was complete resolution of the peri-apical radiolucency. There was no appreciable evidence of root end closure. (Figure 6) Patient did not report after that.

\section{DISCUSSION}

Apexification treatment has been a routine procedure to treat and preserve immature permanent teeth for many decades. However, apexification technique has several disadvantages. It led to a modification of the traditional $\mathrm{Ca}(\mathrm{OH}) 2$ based apexification procedure to achieve immediate obturation of the canal through the introduction of an artificial barrier of mineral trioxide aggregate (MTA). ${ }^{10}$ In spite of the advantages with MTA, the outcomes of MTA apexification do not vary greatly from those of $\mathrm{Ca}(\mathrm{OH}) 2$ apexification. Thin dentinal walls still present a clinical problem, and the high costs associated with MTA and the difficulties in handling the material to the apical $3-4 \mathrm{~mm}$ may restrict its widespread use. ${ }^{11}$ The initial attempts to regenerate the pulp tissue were conducted by Nygaard Ostby. 8,12

The clinical reports by Iwaya et al.13 and Banchs and Trope $^{14}$ served as the initial attempts that gave a start to a variety of clinical cases leading to a considerable accumulation of evidence. The biological concept of REPs involves the triad of stem cells, scaffold and signalling molecules. These stem cells are introduced into root canals through the intentional laceration of periapical tissue after a thorough disinfection protocol. The growth factors and stem cells from the apical area populate the scaffold, inducing tissue regeneration. ${ }^{15,16}$ As follow-up healing progressed in the upper right central incisor, we used the outcome criteria set by Bukhari et al. which include: complete healing, incomplete healing and failure. ${ }^{17}$

Complete healing was defined as the absence of clinical signs and symptoms, complete resolution of periradicular radiolucency, an increase in the root dentin thickness / length and apical closure. Incomplete healing was defined as the absence of clinical signs and symptoms, the periapical lesion either reduced in size or unchanged with / without radiographic signs of increasing root dentin thickness / length, or apical closure. Finally, "failure" was defined as persistent clinical signs and symptoms and / or increased size of the periradicular lesion.

Based on this set criteria, the outcome for this conducted REP procedure can be classified as a "incomplete healing". A longer follow up period was required to conclude the final outcome. The basic shift in treatment approach towards REP from traditional endodontic therapies, requires a shift in assessment of clinical outcomes. ${ }^{1}, 18$ The success of these procedures must be evaluated by 3 parameters: patients and their legal guardians, clinicians, and researchers. Patientbased outcomes: The preset criteria of success laid out by clinicians and researchers might not always align with the needs and desires of patients. ${ }^{19}$ An ideal treatment, from the patient's perspective would be the one that leads to resolution of pain or the one that prolongs the functional life of an asymptomatic tooth. However, for most clinicians, success also means healing of a periapical lesion. ${ }^{20}$

Clinician-based outcomes: Clinicians evaluate for continued root development and also look for radiographic signs of healing. Various degrees of radiographic root development have been observed in most published studies. The factors that modulate this varied response are largely unknown because correlation with factors such as tooth type, aetiology, sex or age has not been established. ${ }^{21}$ Although these dependent measures add valuable information that can be used to determine whether further interventions are needed, their meaning to patients and their guardians is not entirely clear because their expectation is that the tooth is pain free and functional. Although REPs predictably promote healing of apical periodontitis in more than $90 \%$ of the cases, $, 616,21,22,23$ radiographic root development is far less predictable.

Scientist-based outcomes: Outcomes that are not related directly to the clinical manifestation of the treated tooth but that address a specific question that requires scientific methodology in its evaluation should be categorised as scientist-based outcomes. Histologic evaluation of teeth that were treated previously with REPs but later extracted because of recurring trauma and fractures suggests that the newly formed tissue does not resemble the lost dental pulp. This is the best example of a scientist-based outcome because it has strong scientific merit, but it does not necessarily interfere with consideration of the rate of healing and continued root development seen in cases treated with REPs. ${ }^{24,25,26}$ The current protocol of REP that lacks mechanical debridement of biofilm on the canal walls is able to effectively eliminate most intracanal bacteria. But in a case report by Lin et al.,27 it was seen that most of the bacteria were eliminated in the coronal area but not in the apical area of the infected root canal. Therefore, effectiveness of current protocol for REP must be determined to improve the success of revascularisation / revitalisation therapy.

\section{CONCLUSIONS}

Substantial advances in regenerative endodontics are allowing for a better understanding of a multitude of factors that govern stem cell-mediated regeneration and repair of the damaged pulp-dentin complex. Translational research is crucial in 
making these procedures more predictable while pushing the boundaries of future procedures that are likely to involve the direct clinical manipulation of scaffolds, growth factors and stem cells. The success rate of revascularisation / revitalisation therapy should be evaluated in long-term clinical outcome studies.

Financial or other competing interests: None.

Disclosure forms provided by the authors are available with the full text of this article at jemds.com.

\section{REFERENCES}

[1] Murray PE, Garcia-Godoy F, Hargreaves KM. Regenerative endodontics: a review of current status and a call for action. J Endod 2007;33(4):377-90.

[2] https://www.aae.org/specialty/clinicalresources/lossary-endodontic-terms/. [edition last updated march 2020]

[3] Rafter M. Apexification: a review. Dent Traumatol 2005;21(1):1-8.

[4] Frank AL. Therapy for the divergent pulpless tooth by continued apical formation. J Am Dent Assoc 1966;72(1):87-93.

[5] Abbott PV. Apexification with calcium hydroxide--when should the dressing be changed? The case for regular dressing changes. Aust Endod J 1998;24(1):27-32.

[6] Jeeruphan T, Jantarat J, Yanpiset K, et al. Mahidol study 1: comparison of radiographic and survival outcomes of immature teeth treated with either regenerative endodontic or apexification methods: a retrospective study. J Endod 2012;38(10):1330-6.

[7] Bansal R, Jain A. Current overview on dental stem cells applications in regenerative dentistry. J Nat Sci Biol Med 2015;6(1):29-34.

[8] Nygaard-Ostby B, Hjortdal O. Tissue formation in the root canal following pulp removal. Scand J Dent Res 1971;79(5):333-49.

[9] Windley W 3rd, Teixeira F, Levin L, et al. Disinfection of immature teeth with a triple antibiotic paste. J Endod 2005;31(6):439-43.

[10] Bakland LK, Andreasen JO. Will mineral trioxide aggregate replace calcium hydroxide in treating pulpal and periodontal healing complications subsequent to dental trauma? A review. Dent Traumatol 2012;28(1):2532.

[11] Hargreaves KM, Diogenes A, Teixeira FB. Treatment options: biological basis of regenerative endodontic procedures. J Endod 2013;39(Suppl 3):S30-43.

[12] Ostby BN. The role of the blood clot in endodontic therapy. An experimental histologic study. Acta Odontol Scand 1961;19:324-53.
[13] Iwaya SI, Ikawa M, Kubota M. Revascularization of an immature permanent tooth with apical periodontitis and sinus tract. Dent Traumatol 2001;17(4):185-7.

[14] Banchs F, Trope M. Revascularization of immature permanent teeth with apical periodontitis: new treatment protocol? J Endod 2004;30(4):196-200.

[15] Albuquerque MT, Valera MC, Nakashima M, et al. Tissueengineering-based strategies for regenerative endodontics. J Dent Res 2014;93(12):1222-31.

[16] Diogenes A, Henry MA, Teixeira FB, et al. An update on clinical regenerative endodontics. Endod Top 2013;28(1):2-23.

[17] Bukhari S, Kohli MR, Setzer F, et al. Outcome of revascularization procedure: a retrospective case series. J Endod 2016;42(12):1752-9.

[18] Huang GT. A paradigm shift in endodontic management of immature teeth: conservation of stem cells for regeneration. J Dent 2008;36(6):379-86.

[19] Barry MJ, Edgman-Levitan S. Shared decision making-pinnacle of patient-centered care. $\mathrm{N}$ Engl J Med 2012;366(9):780-1.

[20] Reit C. Decision strategies in endodontics: on the design of a recall program. Endod Dent Traumatol 1987;3(5):233-9.

[21] Alobaid AS, Cortes LM, Lo J, et al. Radiographic and clinical outcomes of the treatment of immature permanent teeth by revascularization or apexification: a pilot retrospective cohort study. J Endod 2014;40(8):1063-70.

[22] Nagy MM, Tawfik HE, Hashem AA, et al. Regenerative potential of immature permanent teeth with necrotic pulps after different regenerative protocols. J Endod 2014;40(2):192-8.

[23] Chen MYH, Chen KL, Chen CA, et al. Responses of immature permanent teeth with infected necrotic pulp tissue and apical periodontitis/abscess to revascularization procedures. Int Endod J 2012;45(3):294-305.

[24] Becerra P, Ricucci D, Loghin S, et al. Histologic study of a human immature permanent premolar with chronic apical abscess after revascularization/revitalization. J Endod 2014;40(1):133-9.

[25] Shimizu E, Ricucci D, Albert J, et al. Clinical, radiographic and histological observation of a human immature permanent tooth with chronic apical abscess after revitalization treatment. J Endod 2013;39(8):1078-83.

[26] Martin G, Ricucci D, Gibbs JL, et al. Histological findings of revascularized/revitalized immature permanent molar with apical periodontitis using platelet-rich plasma. J Endod 2013;39(1):138-44.

[27] Lin LM, Shimizu E, Gibbs JL, et al. Histologic and histobacteriologic observations of failed revascularization/revitalization therapy: a case report. J Endod 2014;40(2):291-5. 